\title{
Cancer Diagnosis Program
}

National Cancer Institute

\section{Source}

National Cancer Institute. Cancer Diagnosis Program. NCI Thesaurus. Code C82662.

A program within the National Cancer Institute that stimulates and supports diagnostics research, resources and improved technologies to guide the choice of treatment for cancer patients. 